\title{
Guidance on Dose Rate Measurements for Use in Dose-to-Curie Conversions
}

by

R. S. Howell

Westinghouse Savannah River Company

Savannah River Site

Aiken, South Carolina 29808

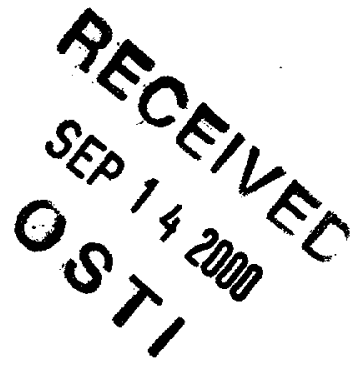

This paper was prepared in connection with work done under the above contract number with the U.S. Department of Energy. By acceptance of this paper, the publisher and/or recipient acknowledges the U. S. Government's right to retain a nonexclusive, royalty-free license in and to any copyright covering this paper, along with the right to reproduce and to authorize others to reproduce all or part of the copyrighted paper. 


\section{DISCLAIMER}

This report was prepared as an account of work sponsored by an agency of the United States Government. Neither the United States Government nor any agency thereof, nor any of their employees, makes any warranty, express or implied, or assumes any legal liability or responsibility for the accuracy, completeness, or usefulness of any information, apparatus, product or process disclosed, or represents that its use would not infringe privately owned rights. Reference herein to any specific commercial product, process or service by trade name, trademark, manufacturer, or otherwise does not necessarily constitute or imply its endorsement, recommendation, or favoring by the United States Government or any agency thereof. The views and opinions of authors expressed herein do not necessarily state or reflect those of the United States Government or any agency thereof.

This report has been reproduced directly from the best available copy.

Available for sale to the public, in paper, from: U.S. Department of Commerce, National Technical Information Service, 5285 Port Royal Road, Springfield, VA 22161, phone: (800) 553-6847

fax: (703) 605-6900

email: orders@ntis.fedworld.gov

online ordering: http://www.ntis.gov/ordering.htm

Available electronically at http://www.doe.gov/bridge

Available for a processing fee to U.S. Department of Energy and its contractors, in paper, from: U.S. Department of Energy, Office of Scientific and Technical Information, P.O. Box 62, Oak Ridge, TN 37831-0062, phone: (865) 576-8401

fax: (865) 576-5728

email: reports@adonis.osti.gov 


\section{DISCLAIMER}

Portions of this document may be illegible in electronic image products. Images are produced from the best available original document. 

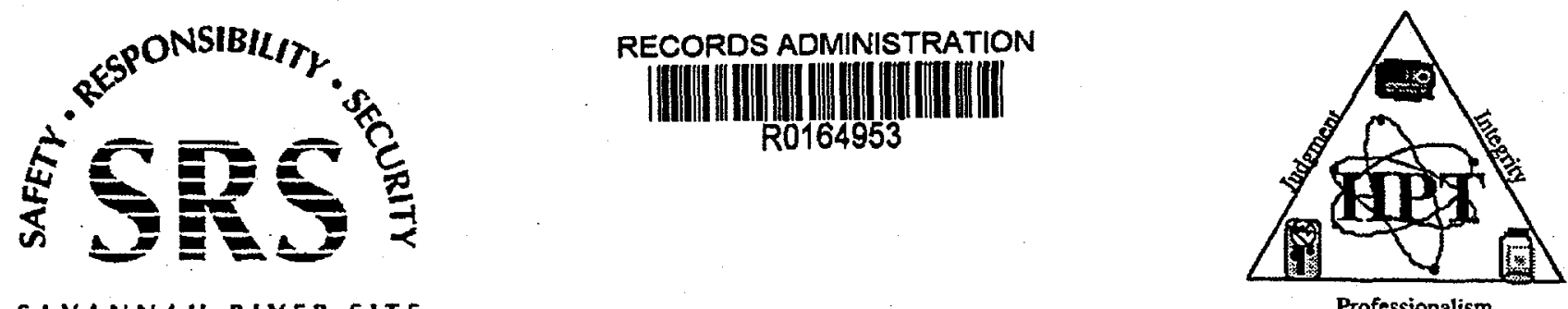

Professionalism

Guidance on Dose Rate Measurements for Use in Dose-to-Curie Conversions (U)

March 2, 1999

By

R. S. Howell, Ph.D.

Westinghouse Savannah River Company Safety \& Health Operations Department

Health Physics Technology

Reviewed:

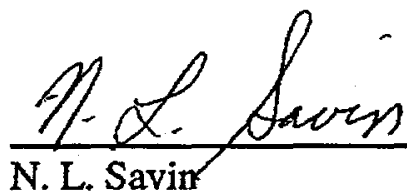

Health Physics Technology - Technical Support Group

Approved: R. R. Rerel

A. R. Goodwyn, Manager

Health Physics Technology - Technical Support Group 
Guidance on Dose Rate Measurements for Use in Dose-to-Curie Conversions (U)

\section{Introduction}

The dose-to-curie (DTC) methodology used at SRS was developed in early 1994 by Health Physics Technology (HPT) for inclusion in the Site Waste Information Tracking System (WITS). DTC is used to estimate the nuclide activity in a waste container based on the measured dose rate from the container. The DTC method is a simple and easy to apply method that can provide a reasonable estimate of the container activity by nuclide when properly applied. In order to make the method practical, numerous assumptions had to be made and limitations placed on its use. Many of these assumptions and limitations are controlled by WITS and are transparent to the individuals making the dose rate measurements and performing the final DTC data input in WITS. However, other limitations can only be procedurally controlled and must be well understood by these individuals in order to assure proper application of the method. These limitations are addressed in this report.

In order to understand and appreciate the limitations on the dose rate measurements for DTC conversions it is necessary to have a basic understanding of the DTC method and assumptions. The method is based on the fact that for a given set of parameters the measured dose rate is proportional to the activity in the container. These parameters include the following:

- Waste container geometry

- Waste container construction material

- Radionuclides contained in the waste matrix

- Waste matrix composition and density

- Waste matrix and radionuclide spatial distribution in the container

- Distance from and location of the radiation detector with respect to the container surface

- Energy response of the radiation detector

- Radiation background (natural and man made).

WITS contains DTC data sets for numerous waste container/waste form combinations (e.g., B-25 containing job control waste). Each DTC data set consists of a matrix of dose rates per Curie of nuclide as a function of waste form density and radionuclide. In order to keep the number of data sets manageable, several assumptions had to be made. These include the following:

- The waste form is uniformly distributed within the container

- The radioactivity is uniformly distributed within the container

- The waste container is full

- The dose rate is measured at a fixed distance and relative location with respect to the container surface 
ESH-HPT-99-0019, Rev. 1

March 2, 1999

Page 2 of 11

- The measured dose rate does not include contributions from other sources of radiation (i.e., natural or man made)

- The instrument used to measure the dose rate has a relative response that is independent of energy.

Details of these assumptions and their effects on the limitations on the dose rate measurements are provided in the following sections. Guidance is also included to assist the user in making proper measurements and entering valid data in WITS.

\section{Background Radiation}

As indicated in the previous section, the activity in a waste container is proportional to the dose rate resulting from radiation emanating from the container. Unfortunately, when dose rate measurements are made the instrument can not distinguish radiation from the waste container from that emitted from any other source. Radiation from sources other than the waste container has two effects on the DTC estimate of activity. The first is to add to the dose rate and, therefore, artificially increase the estimate of the activity in the container. The second is to impact the minimum detectable activity in the container. This issue will be addressed further in the Instrumentation section.

Since radiation dose rate instruments can not distinguish between background radiation and radiation emanating from a waste container the measured dose rate will always be higher than the dose rate that would result from the activity in the waste box alone. Therefore, if all other parameters were known exactly, the DTC estimate of the activity would be high if the background radiation were not accounted for. At SRS the background radiation is composed of both natural background and man made sources (e.g., other waste containers) near the waste container being characterized. The degree to which the activity would be over estimated depends on both the dose rate from the container and the background dose rate. For example, if a waste container has a dose rate of $20 \mu \mathrm{rem} / \mathrm{hr}$ and the background is $180 \mu \mathrm{rem} / \mathrm{hr}$ (natural plus other waste containers) the measured dose rate would be $200 \mu \mathrm{rem} / \mathrm{hr}$. In this case, not accounting for the background would result in an over estimate of the container activity by a factor of 10 . On the other hand, if the waste container has a dose rate of $5000 \mu \mathrm{rem} / \mathrm{hr}$ and the background dose rate is $20 \mu \mathrm{rem} / \mathrm{hr}$ (natural only) the measured dose rate would be $5020 \mu \mathrm{rem} / \mathrm{hr}$. This dose rate would be indistinguishable from the container dose rate. Therefore, there would be no real over estimate of the container activity for this example.

As a result of the potential effect on DTC activity estimates caused by background radiation the following actions should be considered.

- A background dose rate measurement (general area dose rate) should be made in the area that the waste container dose rate is to be made. This measurement should be made just prior to moving the waste container in to the area. 
ESH-HPT-99-0019, Rev. 1

March 2, 1999

Page 3 of 11

- Each waste container should be isolated from other sources of radiation during the DTC dose rate measurement.

- Background dose rate in the area of DTC dose rate measurements should be constant and minimized during the time that DTC dose rate measurements are being made. That is, other sources of radiation should not be transported through the area.

- Background radiation should be subtracted from the DTC dose rate measurement. It must be cautioned that the DTC dose rate, following background subtraction, should never be less than or equal to zero. This will be discussed further in the Instrumentation section.

\section{Instrumentation}

As mentioned in the Introduction, the DTC data used in WTTS are dose rate per Curie of nuclide. These are calculated values where the dose rate is the true tissue dose equivalent rate $(\mathrm{mrem} / \mathrm{hr}$ ) produced only by the gamma rays emitted by the nuclide. For this reason the dose rate instrument must provide the dose equivalent rate. It is also important to realize that the true dose rate relative to the measured dose rate varies with energy for most radiation detectors. Most dose rate instruments tend to under respond at low photon energies such as those produced by transuranic nuclides. Because of the number of different types of dose rate instruments used at SRS, it was not deemed practical to provide different DTC data sets for each instrument. However, neither was this consideration ignored in development and implementation of the DTC methodology at SRS. One instrument used at SRS provides both the desired dose rate and relative response function. The Bicron Micro Rem LE has a tissue equivalent response (i.e., dose equivalent rate in $\mu \mathrm{rem} / \mathrm{hr}$ ). This instrument also has an energy response that provides the true dose rate within $\pm 10 \%$ in the energy range of $16 \mathrm{keV}$ to $1.3 \mathrm{MeV}$. A third advantage of this instrument is its operating range is natural background to $200 \mathrm{mrem} / \mathrm{hr}$. These characteristics make the Bicron Micro Rem LE the instrument of choice for DTC measurements at SRS.

Unlike many dose/exposure rate instruments, the Bicron Micro Rem LE will always give a measurable dose rate. In the absence of all other sources this reading will correspond to natural background and be in the range of -10 to $20 \mu \mathrm{rem} / \mathrm{hr}$. When making measurements below about $50 \mu \mathrm{rem} / \mathrm{hr}$ there are significant fluctuations in the meter reading. This makes it difficult to distinguish actual dose rates of less than approximately 15 $\mu \mathrm{rem} / \mathrm{hr}$ above background from the background reading. For this reason, it is recommend that $15 \mu \mathrm{rem} / \mathrm{hr}$ be used as the minimum sensitivity of the Bicron Micro Rem LE when the background is less than $50 \mu \mathrm{rem} / \mathrm{hr}$. DTC dose rate measurements in backgrounds above $50 \mu \mathrm{rem} / \mathrm{hr}$ are not recommended. However, for those unusual cases where backgrounds of 50 to $200 \mu \mathrm{rem} / \mathrm{hr}$ can not be avoided it is recommended that the minimum sensitivity of $20 \mu \mathrm{rem} / \mathrm{hr}$ be used. Solid Waste Generator Services should be consulted for the proper minimum sensitivity when the radiation background exceeds 200 
ESH-HPT-99-0019, Rev. 1

March 2, 1999

Page 4 of 11

$\mu \mathrm{rem} / \mathrm{hr}$. The minimum sensitivity of the instrument is the dose rate value that should be used in the DTC conversion when the DTC dose rate measurement is indistinguishable from the background measurement. That is, when subtracting background from the DTC dose rate measurement the result should never be less than the minimum sensitivity of the instrument.

The following is a summary of the recommendations pertaining to dose rate measurements made for DTC purposes.

- The Bicron Micro Rem LE should be used for all DTC dose rate measurements.

- Radiation background measurements should be made and subtracted from the DTC dose rate measurement.

- Radiation background should be minimized and constant during DTC dose rate measurements.

- The lowest dose rate value used in DTC conversions should be the minimum sensitivity of the instrument.

- The minimum sensitivity of the Bicron Micro Rem LE is considered to be 15 $\mu \mathrm{rem} / \mathrm{hr}$ for backgrounds of less than $50 \mu \mathrm{rem} / \mathrm{hr}$ and $20 \mu \mathrm{rem} / \mathrm{hr}$ for backgrounds between 50 and $200 \mu \mathrm{rem} / \mathrm{hr}$.

- No shielding may exist between the container and the detector.

\section{Dose Rate Location and Distance}

The radiation dose rate resulting from gamma rays emanating from a waste container is a function of both distance from the container and location of the detector with respect to the container surface. A single dose rate location had to be used in calculating the DTC factors for each waste container type in order to keep the number of data sets to a manageable number. The detector location for each waste container type was selected to help minimize errors caused by variations in placement of the detector during dose rate measurements and variations in actual waste and radionuclide spatial distributions with respect to the assumed distributions.

In making DTC dose rate measurements, variations in the position of the detector with respect to the position used in calculating the DTC data will result in errors in the activity estimates. Placement errors can be either lateral displacement or displacement with respect to distance from the surface. By using a detector location near the center of a surface of the waste container the lateral displacement errors can be minimized. Consequently, detector locations were selected in the center of a container surface. To minimize the effect of displacement of the detector with respect to distance from the container surface it is best to select a detector location far from the container. However, selection of a distant detector location must be tempered with practicality and the ability to detect low levels of activity in the containers. That is, the greater the detector distance the larger 
ESH-HPT-99-0019, Rev. 1

March 2, 1999

Page 5 of 11

the activity required to create a dose rate equal to or greater than the minimum sensitivity of the dose rate instrument.

Both of the conditions described above for selection of the detector location also help to minimize errors resulting from deviations in the assumed homogeneous distributions of the activity and waste form within the container. One other measure that helps to prevent under estimation of activity in the container as a result of nonhomogeneous distribution of the waste form or activity is to take dose rate measurements on multiple surfaces of the container (as directed in Table 1) and use the highest reading.

Table 1 provides a list of the container types with the required detector location and distance from the surface of each. These distances range from $5 \mathrm{~cm}(0.164 \mathrm{ft})$ to 5 . The 5 $\mathrm{cm}$ distance corresponds to the typical "contact" rate measured by the Radiological Control Organization (RCO) and for most instruments is approximately the distance from the face of the detector to the center of the detector. For DTC measurements the distances of $3^{\prime}$ to $5^{\prime}$ are the more ideal distances for minimizing error.

It should be noted that some waste streams require dose rate measurements to be made 5 $\mathrm{cm}$ from the surface of the container. Other waste streams allow the measurements to be made at distances of $3^{\prime}$ to $5^{\prime}$ from the same container type. From the above discussion, it should be realized that these near surface measurements are not ideal. The waste streams requiring the near surface dose rate measurements all contain TRU radionuclides. These detector locations are required because of the extremely low levels of TRU activity that will result in a package being classified as TRU waste. In order to be able to detect these low levels, it is necessary to place the detector in close proximity to the container and take the readings in low background areas.

For those containers requiring distant dose rate measurements, it is realized that it may not always be possible or practical to make the DTC measurements at the desired distance. This may be because of physical constraints or interference from other sources. These conditions should be corrected if possible. Also, a container dose rate may not be detectable at the required distance while one may be detected at a closer distance. Using the dose rate at the closer distance will provide a better, or at least less conservative, estimate of the container activity. As a result, a geometry correction methodology was developed for these situations. This method allows a dose rate to be measured closer to the container than the standard distance and then adjusted to give the equivalent dose rate at the standard distance. This method depends on the relative dose rate as a function of distance from the specific container. The relative dose rate is shown in Figures 1 through 3 for 21 " box, B-12, and B-25 geometries, respectively. The dose rates shown in these figures are relative to the dose rate at a distance of $5 \mathrm{~cm}(0.164 \mathrm{ft})$ from the surface of the container. The polynomial fit for each curve is also provided in the figures. In these equations $\mathrm{x}$ is the distance in feet from the surface of the container to the point where the dose rate measurement is made and $y$ is the relative dose rate (i.e., $D R(x) / D R(0.164 f t)$ ). 
ESH-HPT-99-0019, Rev. 1

March 2, 1999

Page 6 of 11

Table 2 provides geometry correction factors (CF) for various distances. These factors are based on the polynomial functions provided in Figures 1 through 3. A dose rate measurements taken at one of the distances shown in Table 2 is multiplied by the corresponding correction factor to obtain the equivalent dose rate for the package at the standard distance. For dose rate measurement distances other than those provided in Table 2 the poiynomial equation provided in the appropriate figure must be used. For these cases the correction factor is determined using the following equation.

$$
\mathrm{CF}=\mathrm{Y}(\mathrm{s}) / \mathrm{Y}(\mathrm{x})
$$

Where,

$\mathrm{CF}$ is the geometry correction factor,

$\mathrm{Y}(\mathrm{s})$ is the relative dose rate at the standard distance $\mathrm{s}, \mathrm{ft}$, and

$Y(x)$ is the relative dose rate at distance $x$, distance at which the dose rate was measured, $\mathrm{ft}$.

It is cautioned that the polynomial functions shown in these figures MUST NOT be used outside the plotted ranges. That is, dose rates can only be measured and corrected in the range of $5 \mathrm{~cm}$ to $3 \mathrm{ft}$ for the $21^{\prime \prime}$ box geometry and $5 \mathrm{~cm}$ to $5 \mathrm{ft}$ for the B-12 and B-25 geometries.

Use of the correction factor is illustrated in the following examples.

21" Box:

Background - $20 \mu \mathrm{rem} / \mathrm{hr}$

Dose rate measured at $5 \mathrm{~cm}-300 \mu \mathrm{rem} / \mathrm{hr}$

Correction factor from Table $2-0.059$

Dose rate estimate at $3^{\prime}-(300-20) \mu \mathrm{rem} / \mathrm{hr} * 0.059=17 \mu \mathrm{rem} / \mathrm{hr}$

(Enter $17 \mu \mathrm{rem} / \mathrm{hr}$ in WITS as container dose rate.)

B-12:

Background - $30 \mu \mathrm{rem} / \mathrm{hr}$

Dose rate measured at $2 \mathrm{ft}-100 \mu \mathrm{rem} / \mathrm{hr}$

Correction factor from Table $2-0.31$

Dose rate estimate at $5^{\prime}-(100-30) \mu \mathrm{rem} / \mathrm{hr} * 0.31=22 \mu \mathrm{rem} / \mathrm{hr}$

(Enter $22 \mu \mathrm{rem} / \mathrm{hr}$ in WITS as container dose rate.)

B-25:

Background - $20 \mu \mathrm{rem} / \mathrm{hr}$

Dose rate measured at $1.5^{\prime}-90 \mu \mathrm{rem} / \mathrm{hr}$

Relative dose rate at 1.5' determined from equation in Figure 3

$Y(1.5)=-1.426 \mathrm{E}-3 * 1.5^{5}+2.266 \mathrm{E}-2 * 1.5^{4}-1.44 \mathrm{E}-1 * 1.5^{3}+4.817 \mathrm{E}-1 * 1.5^{2}$ 
ESH-HPT-99-0019, Rev. 1

March 2, 1999

Page 7 of 11

$-9.569 \mathrm{E}-1 * 1.5+1.144=0.410$

Relative dose rate at $5^{\prime}$ determined from equation in Figure 3

$\mathrm{Y}(5)=-1.426 \mathrm{E}-3 * 5^{5}+2.266 \mathrm{E}-2 * 5^{4}-1.44 \mathrm{E}-1 * 5^{3}+4.817 \mathrm{E}-1 * 5^{2}$

$-9.569 \mathrm{E}-1 * 5+1.144=0.108$

Correction factor $=Y(5) / Y(1.5)=0.108 / 0.410=0.26$

Dose rate estimate at $5^{\prime}=(90-20) \mu \mathrm{rem} / \mathrm{hr} * 0.26=18 \mu \mathrm{rem} / \mathrm{hr}$

(Enter $18 \mu \mathrm{rem} / \mathrm{hr}$ in WTTS as container dose rate.)

\section{B-25:}

Background $-20 \mu \mathrm{rem} / \mathrm{hr}$

Dose rate measured at $5^{\prime}$ - Indistinguishable from background, in this case the facility procedure calls for taking a dose rate at $5 \mathrm{~cm}$ and correcting to a 5 ' rate.

Dose rate measured at $5 \mathrm{~cm}(0.164 \mathrm{ft})$ - Indistinguishable from background, therefore, dose rate (with background subtracted) is default value of $15 \mu \mathrm{rem} / \mathrm{hr}$.

Correction factor from Table $2=0.11$

Dose rate estimate at $5^{\prime}=15 \mu \mathrm{rem} / \mathrm{hr} * 0.11=1.7 \mu \mathrm{rem} / \mathrm{hr}$

(Enter $1.7 \mu \mathrm{rem} / \mathrm{hr}$ in WITS as container dose rate. Note - Through use of correction factor it is acceptable to enter a dose rate of less than the default in WTS as the "measured" dose rate. This is the only time that this practice is acceptable.)

\section{B-25:}

Background - $15 \mu \mathrm{rem} / \mathrm{hr}$

Dose rate measured at $5^{\prime}$ - Estimated to be $20 \mu \mathrm{rem} / \mathrm{hr}$ (This rate is not truly distinguishable from background. In this case the reading would have to be at least $30 \mu \mathrm{rem} / \mathrm{hr}$ to be distinguishable from background). Therefore, use the default dose rate of $15 \mu \mathrm{rem} / \mathrm{hr}$ as the dose rate from the container.

(Enter $15 \mu \mathrm{rem} / \mathrm{hr}$ in WTTS as the container dose rate.) 
ESH-HPT-99-0019, Rev. 1

March 2, 1999

Page 8 of 11

Table 1

Standard Distances and Locations for DTC Dose Rate Measurements

\begin{tabular}{|c|c|c|c|}
\hline & \multicolumn{2}{|c|}{ Dose Rate Measurement Position } & \\
\hline Container Type & $\begin{array}{l}\text { Distance from } \\
\text { Surface, } \mathrm{ft}\end{array}$ & Location & Comment \\
\hline Yellow B-25 & 5 & All Sides/Ends & \\
\hline Yellow B-25 & 0.164 & Top (open) & F/H-Canyons - See note \\
\hline Yellow B-25 & 0.164 & All Sides/Ends & CLAB \\
\hline Yellow B-25 & 0.164 & All Sides/Ends & SRTC - HEPA filters only \\
\hline Purple B-25 & 5 & All Sides/Ends & \\
\hline B-12 & 5 & All Sides/Ends & \\
\hline B-12 & 0.164 & All Sides/Ends & Saltstone \\
\hline 21" Cardboard Box & 0.164 & All Sides/Top/Bottom & F/H-Canyons \\
\hline 21"Cardboard Box & 3 & Four Sides & \\
\hline 55-gal. Drum & 3 & Side & \\
\hline 55-gal. Drum Liner & 0.164 & Side & CLAB \\
\hline 2 Gallon Pail & 0.164 & Top & CLAB \\
\hline $\mathrm{HIC}$ & 3 & Side & Reactors \\
\hline Skip Pan, 6 yd $^{3}$ & 5 & Both Sides & \\
\hline
\end{tabular}

Note - Occasional use only for asbestos and wood waste.

Table 2

Dose Rate Correction Factors

\begin{tabular}{|c|c|c|c|c|c|c|}
\cline { 2 - 7 } \multicolumn{1}{c|}{} & \multicolumn{6}{c|}{ Correction Factor } \\
\hline Container Type & 0.164 & 1.0 & 2.0 & 3.0 & 4.0 & 5.0 \\
\hline 21" Box & 0.059 & 0.20 & 0.49 & 1.0 & - & - \\
\hline B-12 & 0.086 & 0.18 & 0.31 & 0.49 & 0.71 & 1.0 \\
\hline B-25 & 0.11 & 0.20 & 0.34 & 0.52 & 0.73 & 1.0 \\
\hline
\end{tabular}


ESH-HPT-99-0019, Rev. 1

March 2, 1999

Page 9 of 11

\section{Figure 1}

\section{Relative Dose Rate - 21" Box}

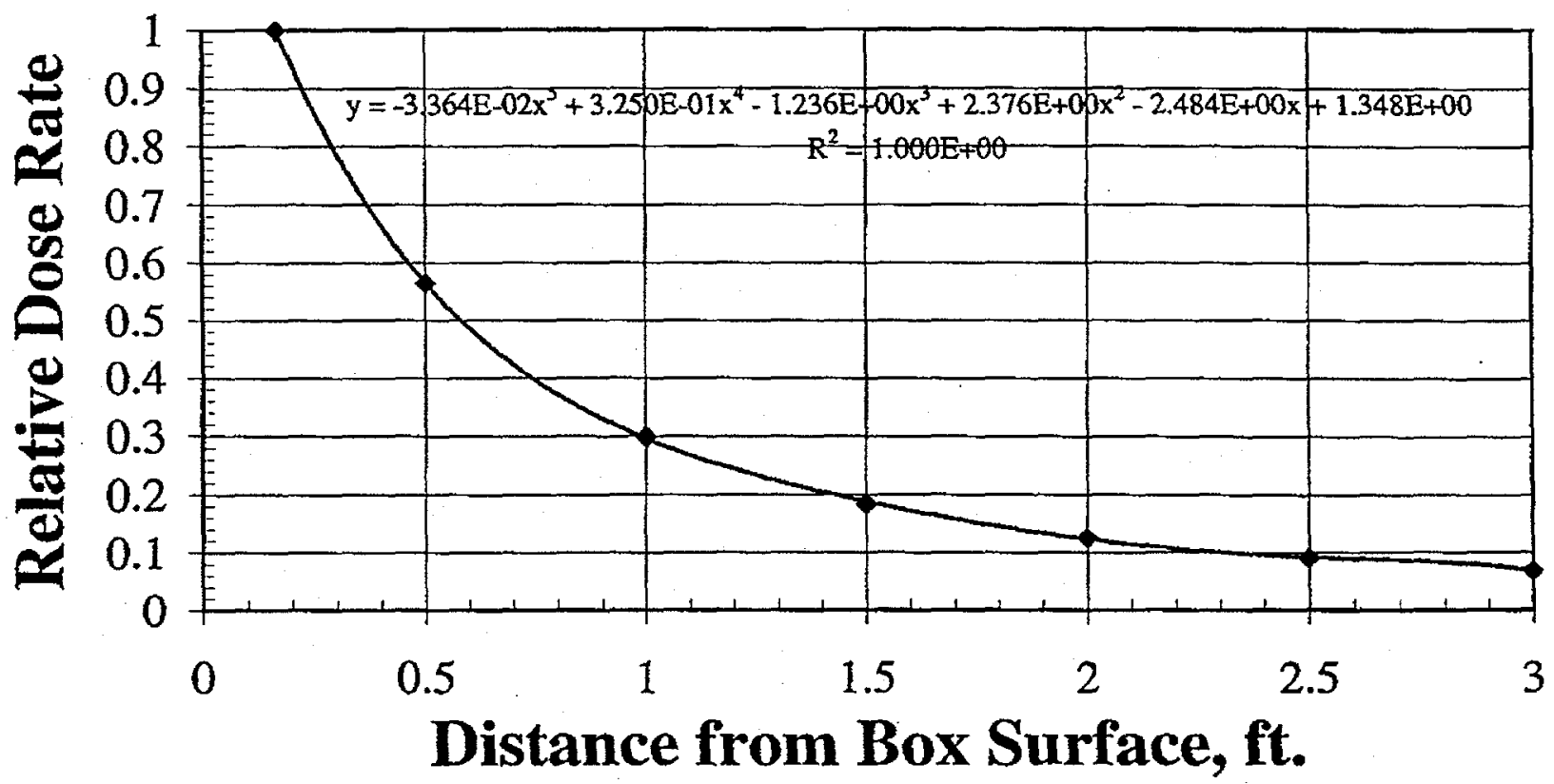


ESH-HPT-99-0019, Rev. 1

March 2, 1999

Page 10 of 11

Figure 2

Relative Dose Rate - B-12

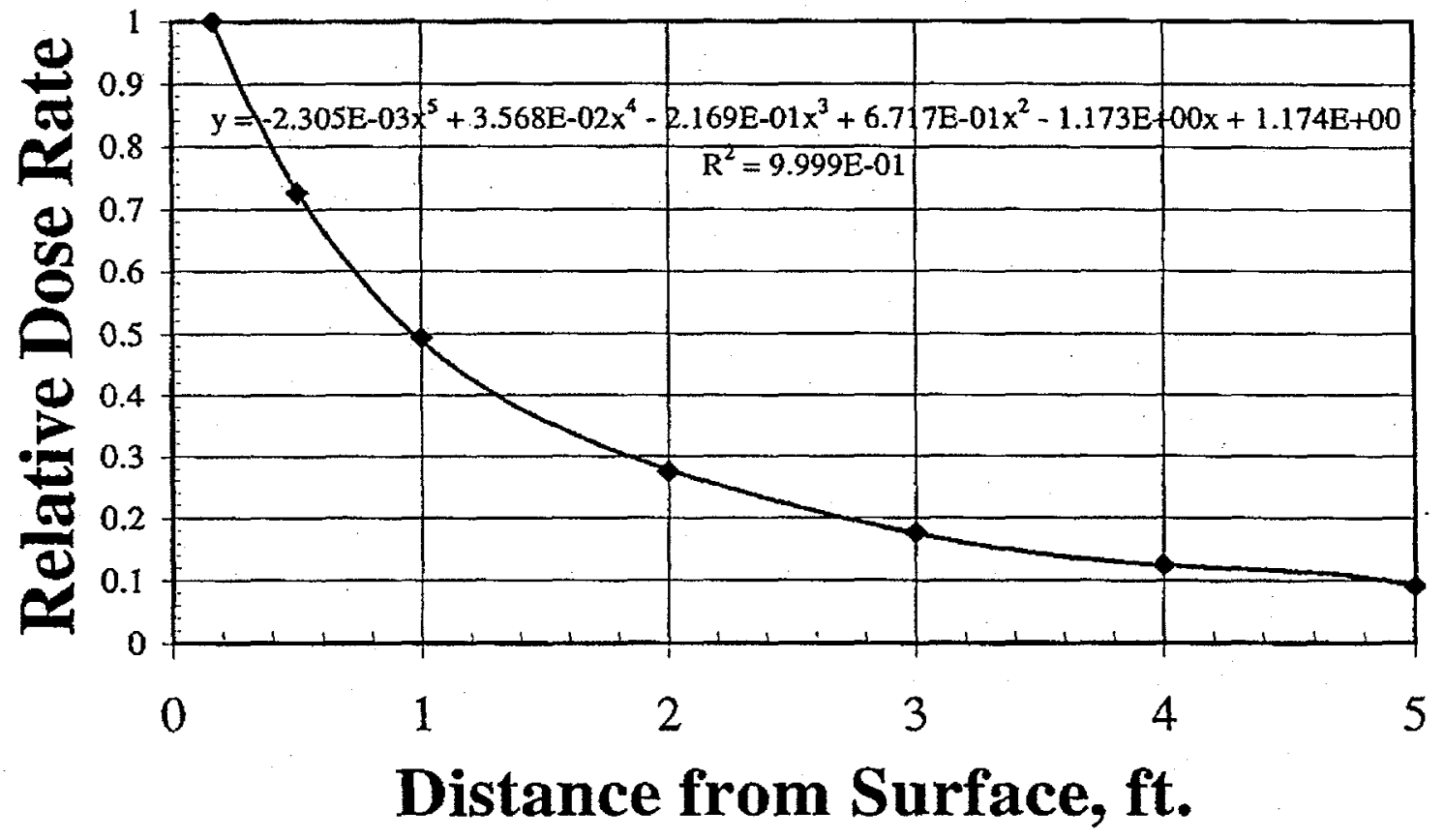


ESH-HPT-99-0019, Rev. 1

March 2, 1999

Page 11 of 11

Figure 3

\section{Relative Dose Rate - B-25}

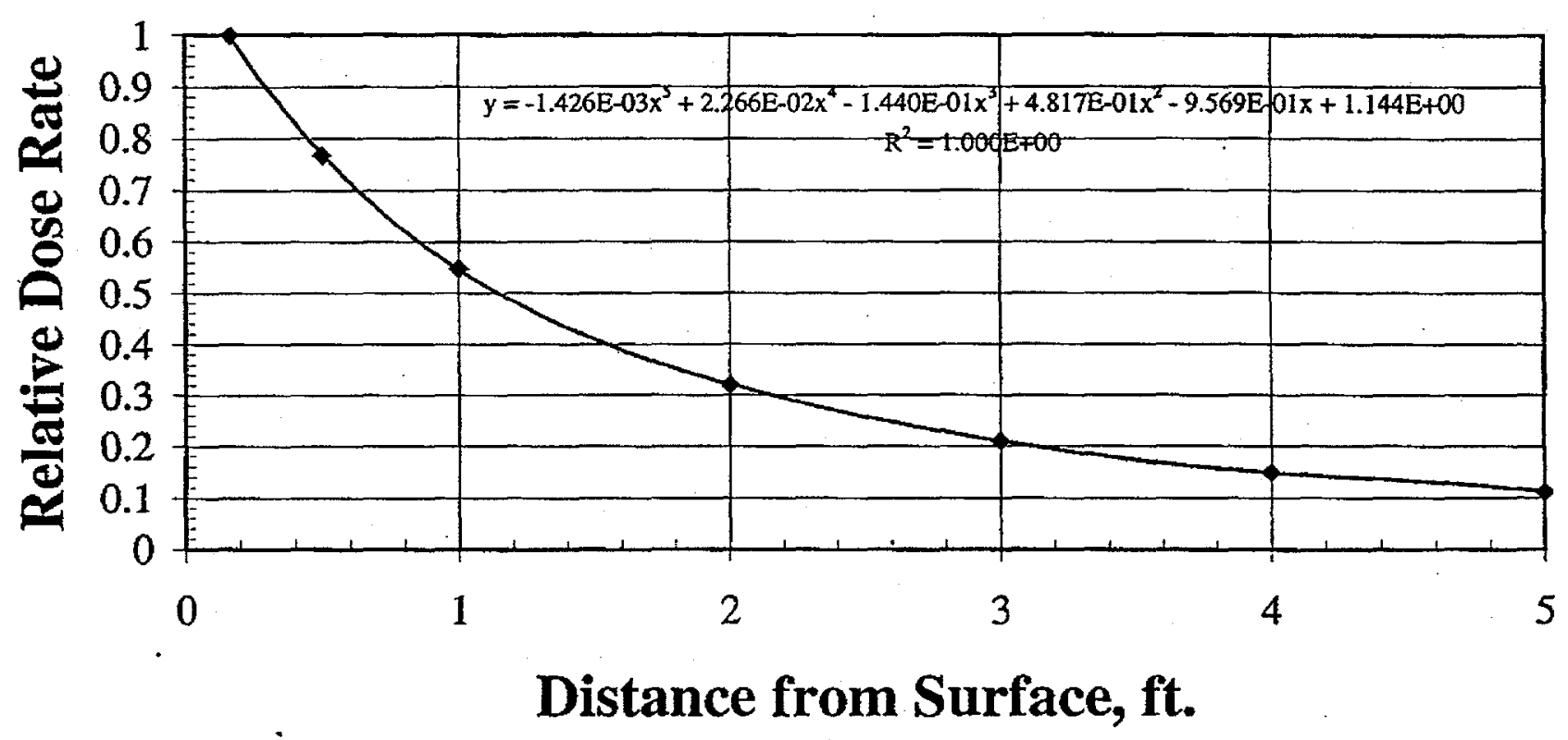

